\title{
Price clustering and underpricing in the IPO aftermarket.
}

\author{
Thanos Verousis (corresponding author) \\ School of Business and Economics, Swansea University, \\ Singleton Park, Swansea, SA2 8PP, UK. \\ Email: t.verousis@swansea.ac.uk \\ Phone number: +44 (0) 1792295364 \\ Owain ap Gwilym \\ Bangor Business School, Bangor University, \\ Bangor, LL57 2DG, UK. \\ Email: owain.apgwilym@bangor.ac.uk \\ Phone number: +44 (0) 1248382176
}

\begin{abstract}
This is the first paper to systematically investigate price clustering in new equity assets using a high frequency transactions dataset. We test the hypotheses that past price information and market maker activities are related to price clustering. We report that price clustering in IPOs is substantially greater than the clustering observed for non-IPO assets, which supports the hypothesis that the decision of going public is followed by haziness about the true price. Underpricing is a significant determinant of price clustering for order-book trades, which supports the notion that underpriced IPOs partially reflect price uncertainties. Tick size specifications can be restrictive for individual investors, while giving execution priority to market makers. The characteristics of price clustering for off-book trades differ substantially to price clustering in the order-book.
\end{abstract}

Keywords: Price clustering; Microstructure; Initial Public Offerings; London Stock Exchange; High-Frequency data

JEL: G14, G12 


\section{Introduction}

Although the underpricing of new equity has been widely researched for over two decades, recent studies have revitalised the interest in the underpricing puzzle (see Chen et al., 2009, Deloof et al., 2009 and Rocholl, 2009). This paper investigates the forces that shape price clustering in initial public offerings (IPOs). Price clustering refers to an unequal distribution of final price digits, reflecting market participants' tendency to concentrate their terms of trading in a smaller set of prices. There is an extensive body of literature that examines the impact of price clustering in the secondary and derivatives' markets (see Harris, 1991, Chung et al., 2004), but less attention has been placed on the primary market. Price clustering in the primary market and the IPO aftermarket ${ }^{1}$ is considered by Bradley et al. (2004) and Mola and Loughran (2004). The focus of the existing literature on IPO price clustering is upon the interaction between the degree of underpricing and clustering, and also the determinants of price clustering in the primary market (Bradley et al., 2004, Torstila, 2003). These issues are strongly influenced by the fact that assets in the primary market do not have a pricing history, so price clustering might also act as a communication channel between the leading underwriters and the primary investors (see Mola and Loughran, 2004).

Bradley et al. (2004) hypothesize that price clustering in the primary market is a function of the degree of uncertainty about a stock's market value. They use the first-day return to verify the hypothesis that the greater the degree of uncertainty, the more extreme is the price clustering. In this paper, this argument is further developed into the secondary market. In particular, it is asserted that the price uncertainty that prevails during the book-building process should also be transmitted to the secondary market. We employ a unique transactions data sample to explore

\footnotetext{
${ }^{1}$ The aftermarket denotes the secondary market trading following a new equity offering (see Ellis et al., 2000).
} 
whether price clustering in the secondary market is a function of the degree of information that is available during the book-building process. The results are compared to assets that have past pricing information and further support is provided for the hypothesis that IPO underpricing reflects price uncertainties. We also document the effect of information-based differences and of market making on the distribution of prices for new equity offerings.

We assert that the price resolution theory (Ball et al, 1985) and the negotiation theory (Harris, 1991) have a common informational element that is identifiable in the price clustering of new equity offerings. In particular, negotiation theory implies that market participants are aware of the available price set, but choose to use a smaller (clustered) price set. Hence, it is assumed that the lack of information about the true value of assets may impair trade negotiations. As a result, traders may focus on a set of clustered prices that does not fully reflect the 'optimum' set that would arise according to the negotiation theory. This leads to an even more prominent clustering phenomenon.

This is the first paper that systematically studies price clustering in IPO and non-IPO issues once they enter the secondary market. Non-IPO issues are defined as firms that are admitted for trading at the exchange's platforms and have past pricing history either by trading in another market/sector or as relisted issues. We fill a gap in the literature by making a direct link between the book-building process and the evolution of prices and trading in the secondary market. Further, while the closely related studies use daily data, we use a high frequency dataset of 99 firms and more than 400,000 observations, which is more in line with the market microstructure literature on underpricing in the IPO aftermarket (Ellis et al., 2000), and price clustering in the secondary and the derivatives markets (see ap Gwilym et al., 1998 and Huang and Stoll, 2001). Particular attention is placed on the UK Alternative Investments' Market (AIM) 
and its differences with the main trading platforms of the London Stock Exchange (LSE). Finally, the effect of different tick size formats is apparent in the results and offers a valuable insight into the design of securities.

The paper's findings support the proposition that IPO underpricing reveals valuable information to investors that is later incorporated in the aftermarket prices. Thus, the decision of going public is followed by price uncertainties that are reflected in price clustering. It is found that price clustering in UK IPOs is prevalent and greater than for UK non-IPOs, reflecting the lack of prior information about the assets' true value. Further, underpricing is a significant determinant of price clustering for order-book trades.

The remainder of the paper is organised as follows. Section II outlines the related literature on price clustering. Section III explains the data selection and data cleaning issues. Section IV discusses the explanatory variables and section V presents the results. Section VI concludes the paper.

\section{Literature Review}

Previous research reports that price clustering in financial markets is a function of price uncertainties (Ball et al., 1985, Aitken et al., 1996) and of the need to minimise trade negotiation costs (Harris, 1991). Also, price clustering reflects investors' attraction to particular numbers (Goodhart and Curcio, 1991) and, given the existence of market makers, the tendency of the latter to maintain wider spreads (Christie and Schultz, 1994). A detailed discussion of competing hypotheses that seek to explain price clustering is given in ap Gwilym et al. (2005) and Chung and Chiang (2006). There is also related literature on optimal tick sizes. Wide spreads can result 
from an artificially large tick size (Booth and Yuksel, 2006), which can also lead to reduced market liquidity (Chung et al., 2005)

To date, the study of price clustering in primary markets has been linked to the effects and origins of underpricing in the underwriting process. ${ }^{2}$ It is argued that clustering cannot only be the result of underpricing during the flotation process (Torstilla, 2003) but is also used as a convention mechanism to reveal underpricing to well-informed investors (Alvarez and Gonzalez, 2005 and Bristow, 1998). Bristow's (1998) study of the distribution and the determinants of IPO prices, covering 25 years of trading and 7,805 US IPOs, reports that $94.7 \%$ of IPO prices are clustered in integers, halves and quarter dollars. ${ }^{3}$ Bradley et al. (2004) report that approximately 75\% of prices of US IPOs issued between 1981 and 2001 were clustered at integer values. Also, Alvarez and Gonzalez (2005) show that the long-run performance of IPOs is positively related to the the initial offer, hence, firms are assumed to underprice their IPOs with a goal to issue higher priced Seasoned Equity Offerings (SEOs) at a later stage.

Kandel et al. (2001) argue that round-number preference can adequately explain price clustering in Israeli IPO auctions (a limit order primary market). They report that, under the IPO limit order rules, investors submit prices that end with 0 in $20 \%$ of cases, compared with the null hypothesis of $10 \%$. However, price clustering in the Israeli IPOs might well be, as in the case of

\footnotetext{
${ }^{2}$ Chen and Ritter (2000) note that U.S. gross spreads (the first-day IPO returns) are persistent at 7\%. Torstilla (2003) validates this finding in several international markets.

${ }^{3}$ The convention in the IPO price clustering literature is to define clustering as the percentage of prices ending in integers.
} 
Bristow $^{4}$ (1998), the actual outcome of limited information about the assets' true value; and an investigation of the IPO returns on the aftermarket might have revealed these information asymmetries. Ascioglu et al. (2007) present evidence that price clustering in the limit-order book of the Tokyo Stock Exchange demonstrates similar behavioural characteristics.

Bradley et al. (2004) hypothesize that IPO price clustering is partially a function of the negotiations occurring during the book building process between the issuing firm and the investment underwriters. They report significant differences in the distributions of initial returns between integer and non-integer offerings for those IPOs whose initial price is set above the original filling price. ${ }^{5}$ Bradley at al. (2004) and Wang (2006) document that the commonly cited determinants of price clustering do not adequately explain the observed price clustering pattern in IPOs. Bradley et al. (2004) report that IPO underpricing is a function of the offer price clustering, the positive price adjustment phenomenon and the level of market-wide underpricing. Also, Bradley et al. (2004) hypothesize that the interaction of issuers with underwriters leads to integer pricing when there is greater price uncertainty (also in Wang, 2006). ${ }^{6}$ In addition, the

\footnotetext{
${ }^{4}$ Bristow (1998) stresses the importance of pricing information, noting that firms that are venture-capital backed are more likely to commence trading on whole integer prices. Such a pattern might be anticipated, since valuation of venture-capital backed firms can be a rather obscure process.

${ }^{5}$ This is known as the partial adjustment phenomenon, originally introduced by Hanley (1993). According to this phenomenon, IPOs are least (most) underpriced when the offer price is set below (above) the original filling price.

${ }^{6}$ Wang (2006) argues that since the IPO clustering pattern continues to affect the aftermarket price clustering level, these uncertainties tend to be transferred to the secondary market.
} 
authors document high volatility in the aftermarket for the whole integer-priced IPOs, which further supports the uncertainty hypothesis. ${ }^{7}$

The findings by Wang (2006) are consistent with the price uncertainty hypothesis and its evolution in the aftermarket. The author documents a continuous fall in integer price frequency for the first 80 trading days after listing, which then becomes stable but still at a level above that for seasoned stocks (see also Ellis, et al., 2000). However, it is possible that the use of higher frequency data could have produced more conclusive findings and additional insights.

Mola and Loughran (2004) show that integer IPO prices generate, on average, a first-day return (gross spread) of $21.4 \%$, which is about three times greater than the return generated from fractional-priced IPOs. They argue that IPO price clustering is a form of signalling to investors (see also Bristow, 1998). ${ }^{8}$ Mola and Loughran $(2004$, p. 26) argue that investment bankers might choose leaving 'more money on the table for their favoured clients' as an indirect form of compensation and extracting economic rents from issuers, which can complement the gross spread clustering. In the same context, Bristow (1998) shows that IPOs priced at $\$ 10$ per share have significantly larger returns on the first two days of trading in the secondary market. ${ }^{9}$

\footnotetext{
${ }^{7}$ Bradley at al. (2004) calculate volatility as the standard deviation of daily stock returns from the $7^{\text {th }}$ day of trading to the $69^{\text {th }}$ day of trading.

${ }^{8}$ There exists a contrast with Chen and Ritter's (2000) 7\% gross-spread clustering convention, which partly arises from the fact that Chen and Ritter (2000) exclude firms with domestic proceeds less than \$20 million since these firms are charged disproportionately high fees due to diseconomies of scale for smaller firms.

${ }^{9}$ However, the author does not give particular insights for the following: if IPO price clustering generates instant large returns then, in the secondary market, the immediate 'correction' of the mispricing should rapidly reduce the extent of price clustering.
} 
In light of the findings in Bradley et al. (2004), we hypothesize that the price clustering that is evident directly after the commencement of IPO trading is a function of price uncertainties and should be more prominent for assets with no past pricing history. The former aspect is reflected in market making activities while the latter aspect makes a distinction between IPO and non-IPO assets. The robustness of our results is further supported by the fact that previous studies have used daily data to document IPO price clustering in the secondary market, whereas we use high frequency data. Ellis et al. (2000) is a unique example using transactions data to study IPO underpricing transmitted to the secondary market. Also, studies on secondary market and derivatives price clustering are almost all focused on the use of high frequency data. For example, ap Gwilym et al (1998) use more than 2.6 million trades and quotes to draw inferences on derivatives price clustering, while Huang and Stoll (2001) employ transactions data from the LSE (1.9 million trades).

\section{The Data}

The data include all trades and quotes for IPOs and non-IPOs (henceforth collectively termed new equity) that commenced trading at the London Stock Exchange (LSE) or the UK Alternative Investments Market (AIM) in 2005. The study focuses on the first 20 trading days that follow the introduction of the offerings to the secondary market. ${ }^{10}$ We employ a transactions database, thus providing a direct link to the norm in the equity price clustering literature. We

\footnotetext{
${ }^{10} \mathrm{We}$ ensure that trading is independent of the conditional trading period of firms. We define $\mathrm{T}$ as the number of trading days $(T=20)$, where $t=0$ denotes the commencement of trading. If the firm has a conditional commencement period, $\mathrm{t}=0$ when the unconditional dealings commence. The book-building process refers to the underwriting period during which investors post indicative quotes within the recommended IPO price band.
} 
select firms that report at least one trade per day for the data period. ${ }^{11}$ The total number of observations for the 99 firms in the sample is $423,307.59 \%(41 \%)$ of trades are in the Q (H) tick (discussed later).

From the transactions' dataset, we identify order-book (automated, AT) and off-book (“ordinary", market maker, MM) trades. ${ }^{12}$ Quotes are standing orders on the order book. In contrast with the order-book trades, trades conducted off-book are not required to adhere to the minimum price increment restrictions. Also, while the order-book is open to all investors, market makers are always on one side of the transaction for off-book trades. ${ }^{13}$ The minimum tick size format at the LSE is a function of the price level and changes for different market segments. Table 1 presents the minimum tick size formats for different market segments. ${ }^{14}$ It follows that price clustering is also a function of the minimum tick size (Chung et al., 2005, Hameed and Terry, 1998).

*** Insert Table 1 about here***

\footnotetext{
${ }^{11}$ The main market includes large capitalisation stocks trading at the LSE. The AIM is a global market designed for smaller firms. In order to study the effect of main market trading, stocks trading at the International Order Book (IOB) are not classified into the main market. Warrants, cancelled, pre-opening, after-hours and zero quotes are discarded. Also, 5 firms with data selection problems (inconsistent tick size, missing observations) were discarded. ${ }^{12} 69 \%$ of trades in the sample are conducted electronically via the order book.

${ }^{13}$ The transactions' dataset identifies market maker-to-market maker trades in a different trade category; hence, offbook trades do not include such trades. LSE officials have confirmed the accuracy of our categorization of trades.

${ }^{14}$ Only formats that are applicable to the current sample are mentioned in the table. We use the exchange's service announcements to guarantee that during the period of the study the tick size for each stock is consistent.
} 
Considering the implications of the classification of trades as order-book or market maker trades, we further hypothesize that price clustering reflects differences in the market microstructure of assets (which we refer to as the "market making hypothesis"). The above implies that, as market makers have different trading objectives from other investors, a distinction between individual ${ }^{15}$ and market maker trades is created (for a cornerstone study of this, see Christie and Schultz, 1994). Hence the market maker hypothesis should actually be reflected in the price clustering for all new equity and a further layer of variation is added to the analysis of IPOs and non-IPOs.

Table 2 indicates that the price clustering of new equity is more prevalent for IPOs. It is also documented that while the issue price for IPOs is much higher than for non-IPOs; albeit, as expected, new assets tend to raise less money from the primary market. ${ }^{16}$ The latter is also reflected in the fact that the vast majority of non-IPOs are admitted for trading at the main market. In the secondary market, IPOs tend to generate larger first-day returns, which may partially reflect the price clustering of assets that prevailed during the book-building process (see Bradley et al., 2004).

***Insert Table 2 about here***

\footnotetext{
15 "Individual investors" refers to both institutional and individual participants. Market makers are also referred to as affiliated members of the exchange.

${ }^{16}$ The mean issue price for non-IPOs reflects 13 firms; the remaining, as expected, did not have any price quotes.
} 


\section{Explanatory Variables in the Multivariate Analysis}

Consistent with previous research on IPO price clustering, the dependent variable is defined as the percentage of prices at integer values for each asset in each time interval. Separate OLS estimations use order-book trades only, off-book trades only and quotes only.

An identifier dummy for IPOs and non-IPOs is used (IPO). We assert that the degree of underpricing can be used as a measure of the price uncertainty that prevailed in the primary market. Consistent with Corwin (2003), underpricing is defined as negative one times the firstday return (Under). ${ }^{17}$ Also, a dummy variable (Fraction) that equals one if the IPO price is quoted in decimals and zero otherwise is expected to further support the Bradley et al. (2004) hypothesis.

Price clustering should be positively correlated with trade size (TS), implying that since the economic impact of the minimum tick size is greater for small trades, investors should use a coarser set of prices for large trades (Harris, 1991). Similarly, transaction frequency $(T F)$ is used to proxy for the underlying value information (see Harris, 1991). We use a segment-specific dummy (Segm) to control for the differences between the main and the alternative (AIM) markets. Also, as large firms are followed by more analysts and are better diversified than small firms (Harris, 1991), price clustering is expected to decrease with firm size (FS).

An issue that has been widely discussed in the IPO literature is the role played by flippers in the determination of IPO prices in the aftermarket (see Fishe, 2002). Flippers buy IPOs in the primary market and then sell them immediately after the introduction in the secondary market,

\footnotetext{
${ }^{17}$ For IPOs, the first-day return is calculated using the first-day return with the IPO price as the price basis. For nonIPOs with no offering price, the first-day return is calculated using the first day's price and the base price is the asset's closing price for the previous day, which is obtained from DataStream.
} 
thus realizing a profit. However, if the IPO is cold i.e. the bid price is less that the IPO price, such practice will be avoided. We use the tick test to infer trade direction (TD), thus, TD gives the percentage of sell orders as a proportion of the overall number of trades. ${ }^{18}$

Following Bradley et al. (2004), it is hypothesized that price uncertainty leads investors to choose from a smaller set of final prices. The authors measure uncertainty in two ways; using the cross-sectional standard deviation of initial returns and calculating the 3-month ex-post standard deviation of daily stock returns, between the $7^{\text {th }}$ and $69^{\text {th }}$ day of trading. However, the use of a forward-looking volatility as a proxy of price uncertainty for IPOs is problematic because volatility levels might not have been established on the first day of trading. Hence, volatility is calculated as the standard deviation of daily log returns ( $V o l$ ) over the 20-day period. It is expected that volatility should have a positive relation with price clustering, since volatile prices reflect greater haziness about an asset's true value.

The negotiation hypothesis (Harris, 1991) suggests that investors have less incentive to use a finer set of prices when the stock's price is smaller, since the minimum tick size represents a greater burden on investors' costs for a small-priced stock. Accordingly, the average daily closing price is used in the analysis $(P L)$. We use a tick-specific (Tick) dummy to control for tick size differences. ${ }^{19}$ Hence, we estimate the following regression model:

$$
\begin{gathered}
\text { Clust }_{i, t}=\beta_{0}+\beta_{1} \text { IPO }_{i}+\beta_{2} \text { Under }_{i}+\beta_{3} \text { Fraction }_{i}+\beta_{4} \text { TS }_{i, t}+\beta_{5} \text { TF }_{i, t}+\beta_{6} \text { Segm }_{i} \\
+\beta_{7} F S_{i, t}+\beta_{8} T D_{i, t}+\beta_{9} \text { Vol }_{i}+\beta_{10} P L+\beta_{11} \text { Tick }_{i}+\varepsilon_{i, t}
\end{gathered}
$$

\footnotetext{
${ }^{18}$ For discussion on trade direction tests, see Finucane (2000).

${ }^{19}$ No evidence of significant correlation amongst the independent variables is detected.
} 
Where, CLUST is the percentage of integer prices for each stock $i$ for each time interval $t$. $I P O$ is an IPO dummy (equals 1 if IPO; 0 otherwise). Under equals negative one times the firstday return. Fraction is a dummy variable that equals 1 if the IPO price is in decimals, zero otherwise. $T S$ is the average trade size per time interval. $T F$ is the inverse square root of the average number of transactions per hour. Segm is a dummy variable that equals 1 if the stock is traded at the main market and 0 otherwise. $F S$ is the natural $\log$ of market capitalization at each day $T . T D$ is the percentage of sell orders as a portion of the overall number of trades per interval. $V O L$ is the standard deviation of returns. $P L$ is the average daily closing price for stock i during the study period. Tick equals 1 if $\mathrm{H}$ tick, 0 if $\mathrm{Q}$ tick.

\section{Analysis}

\subsection{Initial characterisation of price clustering}

In order to enhance comparability with previous research (Bradley at al., 2004; Bristow, 1998; Wang, 2006), an integer clustering definition is implemented. Results are presented in Table 3. It is expected that different tick sizes lead to different price distributions. At an intra-tick level, the difference between order-book and off-book trades is in line with our market making hypothesis. Bradley et al. (2004) link primary market price clustering with the degree of 'haziness' about the firm's fundamental value. Table 3 shows that prices of IPOs are more clustered in the aftermarket than are prices of non-IPOs. This applies for both order-book and off-book trades. This finding supports the proposition that there is less information about fundamental values for IPOs than for non-IPOs.

*** Insert Table 3 about here*** 
More specifically, Panel A of Table 3, presents the distribution of final digits for nonIPOs and IPOs, separately for order-book trades, off-book trades and quotes for the H-tick assets. For order-book trades (AT) there is a substantial difference between non-IPO and IPO cases. This reflects information asymmetries that are likely to prevail at the commencement of trading for IPOs (Harris, 1991, Bradley et al. 2004). For order-book IPO (non-IPO) trades, 85\% (53\%) of executed trades are at integers. For market maker (off-book) trades, the extent of clustering is less pronounced, which at least partly reflects the fact that the minimum tick size is not applicable to off-book trades. For non-IPOs $61 \%$ of trades are executed in prices which are not multiples of the tick size, whilst for non-IPOs the percentage of similarly executed trades is $26 \%$.

Panel B of Table 3 presents the distribution of prices at final decimal digits for the Q-tick assets. Prices for IPOs are concentrated in integers, and there is a clear pattern across all subsamples in the distribution of decimal prices. Whole numbers are more favoured than halfs, and halfs are more favoured than quarters (similar across AT and MM). The $x^{2}$ goodness-of-fit test statistic uniformly rejects the hypothesis that IPOs exhibit the same price distribution as nonIPOs. Also, while a statistically significant difference between IPOs and non-IPOs is observed, the magnitude of the difference is higher for order-book trades, which may signal larger price uncertainties for order-book trades.

Further developing the notion that market structures have a significant impact upon price clustering, Table 4 presents results on integer price clustering for each market segment and new equity issue type (non-IPOs / IPOs). Segments mentioned in Table 4 can be classified to each trading platform according to their trading characteristics. 
***Insert Table 4 about here***

Connolly (2005) notes that market structures make difficult the adaptability of investors to different market segments, thus many investors prefer to identify themselves with the trading in one market segment. Also, Connolly (2005, p. 55) argues that for an electronic order book “...there can be hundreds of iceberg and hidden orders, as well as multiple orders driven by complex algorithmic software, which may in turn be dependent on prices in other assets". On the basis of the above and consistent with Grossman et al. (1997), Table 4 documents a substantial difference between assets that are traded in order-driven platforms (SET1, SET3) and assets that are traded in a quote-driven trading environment (AIM, AIMI, SEAQ, SEQ1). Also, the average percentage of prices at integers for assets traded on SETSmm (SSMM and STMM) is between the average for order-driven and quote-driven platforms, reflecting the fact that SETSmm is a hybrid platform. Table 4 also shows that in those domestic segments where market makers compete with individual investors (SSMM, STMM, SET3, SET1), off-book trades are less clustered in integers than are order-book trades, which partially reflects the informational advantage of market makers over individual investors and the effect of tick size on trades.

Table 5 presents the intraday distribution of clustering at integer prices separately for non-IPOs and IPOs, controlling for tick size and trade type differences. There is a very substantial difference between non-IPO and IPO clustering for both tick sizes. The $x^{2}$ goodnessof-fit test statistic on the paired difference between non-IPOs and IPOs shows that IPO clustering is consistently higher than non-IPOs during the trading day. The average difference between IPOs and non-IPOs for order-book trades is $32 \%(\mathrm{H}$ tick) and $21 \%$ (Q tick), while the average difference for off-book trades is 45\% (H tick) and 9\% (Q tick). As institutional differences in the 
minimum tick size are controlled, Table 5 only reflects information differences across new equity types. Also, it is demonstrated that non-IPOs and IPOs follow a different intraday pattern, especially for order-book trades. Table 5 shows that prices for both order-book and market maker trades for IPOs are more clustered at the beginning of the day, whilst during the trading day price clustering in integers diminishes (even though market maker trades are less volatile throughout most of the day). This finding is consistent with Ohta (2006) and ap Gwilym et al. (1998), and also supports the price resolution hypothesis. The latter implies that, at the market open, investors have less information about the true value of the stock following overnight market closure, thus they tend to trade using a coarser set of prices. As the day progresses information arrives to the market, so price clustering is decreased. The same finding is reported for market maker non-IPO trades, while for order-book non-IPO trades the intraday pattern is different, whereby price clustering is rather stable and is maximised (minimised) during the trading day (towards the market close). As this is inconsistent with previous findings, it may reflect that price clustering at the order-book remains largely unaffected by the dissemination of new information in the market and may actually reflect an established level of clustering for individual investors.

\footnotetext{
***Insert Table 5 about here***
}

As noted by Harris (2003), the minimum tick size can actually be restricting for orderbook trades, hence increasing the transaction costs that investors are required to pay. On the other hand, for off-book trades the cost of acquiring price precedence is very small. Hence, an 
issue that arises regarding the minimum tick size restrictions imposed upon order-book trades is the implications that this policy may have on market makers' trades.

Ascioglu et al. (2007) show that traders step ahead of the limit order book of the Tokyo Stock Exchange by trading one tick below round prices (for buys) and one tick above (for sells). In our context, we hypothesise that market makers gain priority over other investors by buying at prices slightly larger than the minimum tick size and selling at prices slightly smaller than the minimum tick size. ${ }^{20}$ This hypothesis is studied in Figures 1 and 2 for the $\mathrm{H}$ and $\mathrm{Q}$ tick respectively. The tick trade identification method (see Finucane, 2000) is applied in order to classify trades as buys (Plot A) or sells (Plot B).

***Insert Figure 1 about here***

In Figure 1, as it is no surprise that the minimum tick increments (0 and .5) are used as focal points, they are omitted from the plots so that a more detailed picture can emerge. The hypothesis studied here is that market makers exploit the minimum tick restrictions to gain price priority over order-book trades. ${ }^{21}$ Plot A shows that when market makers are on the buy side of a trade the tendency is to trade at multiples of .25. However, two distinctive patterns also emerge. The first is that buy trades are more clustered at prices slightly larger than multiples of the minimum tick size (0 and .5), which is, at least partially, explained by the ability of market makers to gain price priority over the order-book trades. The second distinctive feature of Plot A

\footnotetext{
${ }^{20}$ A similar hypothesis has been studied by Chiao and Wang (2009) but the results are inconclusive.

${ }^{21}$ A small tick size diminishes the effect of the time precedence rule, while a large tick size increases traders' reluctance to improve prices.
} 
is the magnitude of the final digit 9 which can only be explained by the attractiveness of this digit.

The magnitude of digit 9 is also observed in Plot B which shows the distribution of ending prices for sell trades conducted by market makers. Also, Plot B shows that, while for buys the most popular digit was 0.75 , for sells the most popular is 0.25 which clearly reflects the fact that with a minimum tick of 0.5 , price priority for buys is gained at prices larger than 0.5 and for sells at prices slightly smaller than 0.5 . However, even though the Figure may give a strong indication on market makers' trade strategies, no conclusive evidence can be inferred.

Figure 2 plots the distribution of off-book (MM) trades (excluding the multiples of the minimum price format) for the smaller tick size $(\mathrm{Q})$. Plot A shows that the peaks for market maker buys and sells are found at multiples of ten, while other multiples of five follow in the ranking. Also, while the latter may partially reflect that the smaller tick is more beneficial for order-book trades rather than for market makers, the preference of 0.9 is also very visible, especially for sell orders in plot B.

*** Insert Figure 2 about here $* * *$

\subsection{Multivariate Analysis Results}

Table 6 presents the results for the transactions (tick-by-tick) sample aggregated in daily frequencies. Different regressions are employed for off-book and order-book trades and for 
quotes. ${ }^{22}$ First order autocorrelation is detected in the residuals, hence, the results are based on the Newey-West HAC standard error estimates.

As hypothesized, there is a strong positive relationship between IPOs and price clustering. This is consistent for both trades and quotes. IPOs are thus more likely to trade in integers even after controlling for asset characteristics like price level and trade size.

\section{***Insert Table 6 about here***}

For the order-book trades, we verify the hypothesis that price uncertainties that prevail in the primary market tend to be transmitted to the secondary market. Under is positive and statistically significant for AT. However, for the off-book trades, price clustering decreases for the more underpriced assets, which rejects the IPO price uncertainty hypothesis for this sector. Similarly, the Fraction dummy is positive for the order-book trades, which shows that, in contrast to Bradley et al. (2004), more price clustering is associated with those assets initially priced at decimals. The reverse effect is observed for standing orders and market maker trades, however, the finding of Bradley et al. (2004) is statistically validated for standing orders (quotes) only. The above set of variables reveals that order-book price clustering increases with underpricing and is negatively associated with primary market price clustering. In contrast, primary market price clustering is of no statistical significance for market maker trades; also, price clustering is found to decrease with underpricing.

\footnotetext{
${ }^{22}$ The total number of potential intervals for each regression is 1980 . Intervals with no price data are deleted, hence the different values of $\mathrm{N}$.
} 
Consistent with previous findings (Harris, 1991), the average trade size per interval (TS) is found to have a marginal but statistically significant relationship with price clustering for the order-book trades. For standing orders, TS is negatively associated with price clustering, while for market maker trades, no statistical relationship is present. The sign of the estimated coefficient for $T F$ is as expected only for order-book trades and quotes. Harris (1991) observes that since clustering should decrease with transaction frequency, $T F$ is expected to be positive. For both order-book trades and quotes $T F$ is positive and significant, yet for market maker trades the relationship is reversed. This should reflect the fact that market maker trades are not actually affected by the number of transactions executed; instead the reverse sign might indicate the market makers' objective to maximise the number of trades that they fill (see Moulton, 2005).

The market segment dummy is expected to have a negative sign since trading is heavier in the main market. This is the case for trades on the order-book, however, for quotes and offbook trades the results show that a positive relationship is statistically significant. Stocks traded at markets other than the main market are more likely to employ a finer price grid. The latter reflects price clustering in the international main market, as the AIM is much more thinly traded. $^{23}$

Harris (1991) argues that market capitalisation has a negative effect on the degree of price clustering, so the greater the market value of a firm the lesser the degree of price clustering observed (see also Chung et al., 2004). For order-book trades, market value is found to be negatively related with price clustering (as expected). However, there is no statistically

\footnotetext{
${ }^{23}$ As firms traded at AIM tend to be small capitalisation, the regressions were also estimated without the Segment dummy. This had no impact on the signs nor the significance of coefficients on other variables. Also, in separate regressions, an unconditional trading period dummy was used in order to study the effect of conditional trading on the dependent variable. Yet, the results were not significant, thus they are excluded from the analysis.
} 
significant relationship for off-book trades and quotes. Trade direction (TD) is found to have a positive relation with price clustering for off-book trades. This confirms the hypothesis that impatient traders use focal prices when they want to execute their trades faster. The same relationship is not validated for the order book trading facility, however, the latter result is expected as investors who trade via the order-book submit "standing orders" only (see Harris, 2003). Hence, inventory control characteristics may be reflected in TD for off-book trades.

Volatility in order-book trades is a positive determinant of price clustering, which is consistent with previous work (see Harris, 1991) reflecting the fact that individual investors use clustered prices when assets prices are more volatile. However, volatility is negative for the offbook trades. The results on the average closing price confirm previous research on the positive relationship between clustering and price (Chung et al., 2004), which also supports the negotiation theory (Harris, 1991). As expected, price clustering is diminished for the larger tick size.

\section{Conclusion}

This paper fills a void in the equity price clustering literature by studying the origins of the phenomenon in a special setting in which past pricing information is not a prerequisite. In addition, the issue of the influence of market making at the LSE upon price clustering is tackled. The above is conducted in an environment of different tick formats across different market segments. In contrast with previous results (see Wang, 2006, Bradley et al., 2004) the findings

are supported by an intraday high-frequency dataset. We hypothesize that, consistent with Bradley et al. (2004), IPO underpricing reflects price uncertainties about the assets' true market 
value. The above argument is further studied in the secondary market, offering a direct link for the information transmission between the primary and the secondary market.

The results reveal that prices of IPO assets are relatively more clustered in the primary/secondary market than non-IPO assets. This is persistent across all market segments and trading platforms. This validates the hypothesis that the decision of going public is followed by haziness about the true price of the assets. It is found that for order-book trades, the degree of IPO underpricing is positively related to price clustering in the secondary market, supporting the hypothesis that IPO price uncertainties that occur during the book-building process are transmitted to the secondary market. Also, the results reveal that price clustering in the off-book market is inversely affected by undepricing proxies. In general, the characteristics of price clustering for off-book trades differ substantially to price clustering in the order-book, nevertheless, the results on the order-book market generally support the hypotheses and are consistent with previous literature findings.

Transaction data analysis reveals that market making in new equity issues is heavily influenced by information asymmetries between IPOs and non-IPOs. The latter tends to validate the price resolution hypothesis. Also, a weak fit is found for the negotiation hypothesis and intrasegment price clustering differences exist. Finally, it is reported that tick size specifications can be a burden to investors, while the hypothesis that market makers front-run individual investors does not have general validity. 
Table 1: Price Formats in Different Market Segments

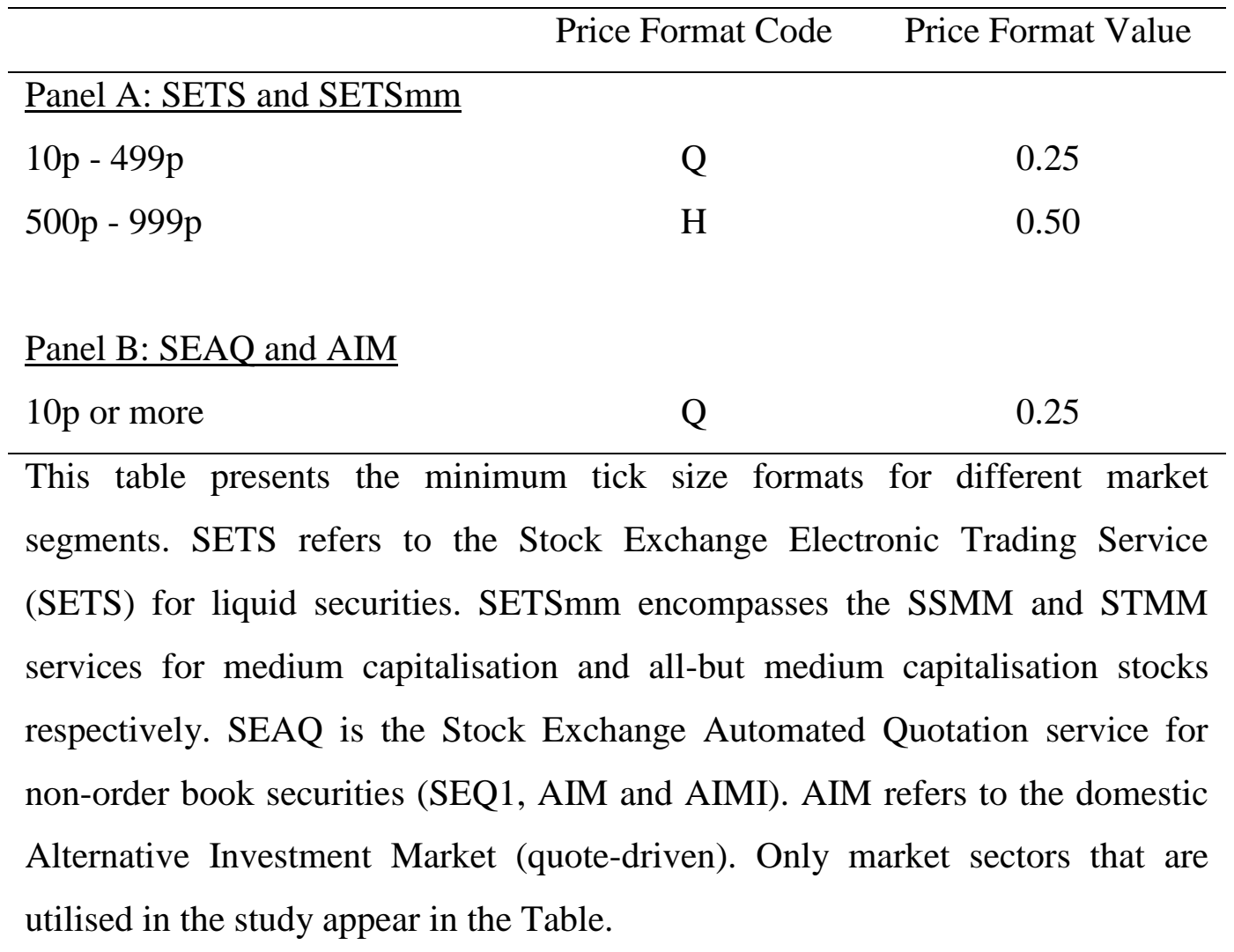


Table 2: Summary Statistics

\begin{tabular}{lll}
\hline New Equity Issue type (Number of firms) & Non-IPO (51) & IPO (48) \\
\hline $\begin{array}{l}\text { Primary Market } \\
\text { Issue Type (\%): }\end{array}$ & $0.00 / 74.51 / 25.49$ & $18.75 / 0.00 / 81.25$ \\
Offering/Introduction/Placing & $93 \%(7 \%)$ & $53 \%(47 \%)$ \\
$\begin{array}{l}\text { Exchange listing: Main (AIM) } \\
\text { Number of new equity at integers }\end{array}$ & $32(19)$ & $46(2)$ \\
(decimals) & 47.76 & $138.05 * * *(4.26)$ \\
Mean Issue Price (t-value) & 631.11 & 313.65 \\
Mean Market value £m (t-value) & & \\
Secondary Market & $47.12)$ \\
Number of Firms per Tick Size: Q (H) & $47(4)$ & $47(1)$ \\
Gross spread per firm \% (t-value) & 7.58 & $17.00^{* *}(1.93)$ \\
Mean number of trades per firm (t-value) & $4,058.71$ & $2,464.04(0.94)$ \\
Mean Trade Price per firm (t-value) & 271.99 & 54.55
\end{tabular}

This table presents the number of new equity (IPOs and non-IPOs) that are priced at integer values, the mean issue price (p), the market value, the distribution of underwriting methods and the percentage of firms accepted at the main and AIM for IPOs and non-IPOs. The second part of this table presents the gross spread (\%), the number of firms per tick size, the mean number of trades and the average trade price (p) figures per firm for IPO and non-IPO issues. In parentheses, the t value for the equality of means. $* *, * * *$ significant at the $5 \%$ and $1 \%$ levels, respectively. 
Table 3: Distribution of Final Digits

\begin{tabular}{|c|c|c|c|c|c|c|c|c|c|c|}
\hline & \multicolumn{3}{|c|}{ Non-IPO } & \multicolumn{3}{|c|}{ IPO } & \multicolumn{4}{|c|}{ Differences } \\
\hline & $\mathrm{AT}$ & MM & Quotes & $\mathrm{AT}$ & MM & Quotes & & $\mathrm{AT}$ & $\mathrm{MM}$ & Quotes \\
\hline INT & $52.6 \%$ & $21.3 \%$ & $53.6 \%$ & $84.6 \%$ & $66.2 \%$ & $74.8 \%$ & INT & $-32.0 \% * * *$ & $-44.9 \% * * *$ & $-21.2 \% * * *$ \\
\hline Other & $0.0 \%$ & $61.5 \%$ & $0.0 \%$ & $0.0 \%$ & $25.6 \%$ & $0.0 \%$ & Other & . & $35.9 \% * * *$ & . \\
\hline $\mathrm{N}$ & $\begin{array}{c}107,573 \\
(0)\end{array}$ & $\begin{array}{c}2,616 \\
(4,171)\end{array}$ & $\begin{array}{c}39774 \\
(0)\end{array}$ & $\begin{array}{c}10674 \\
(0)\end{array}$ & $\begin{array}{l}1,889 \\
(650)\end{array}$ & $\begin{array}{l}7067 \\
(0)\end{array}$ & $x^{2}$ & 4380.83 & 3050.88 & 1271.79 \\
\hline INT & $34.5 \%$ & $25.1 \%$ & $45.1 \%$ & $56.9 \%$ & $34.8 \%$ & $52.3 \%$ & INT & $-22.4 \% * * *$ & $-9.7 \% * * *$ & $-7.2 \% * * *$ \\
\hline 0.25 & $18.9 \%$ & $4.7 \%$ & $15.3 \%$ & $11.2 \%$ & $4.1 \%$ & $12.4 \%$ & 0.25 & $7.7 \% * * *$ & $0.6 \% * * *$ & $2.9 \% * * *$ \\
\hline 0.5 & $24.5 \%$ & $13.8 \%$ & $24.1 \%$ & $22.2 \%$ & $12.1 \%$ & $22.8 \%$ & 0.5 & $2.3 \% * * *$ & $1.7 \% * * *$ & $1.3 \% * * *$ \\
\hline 0.75 & $22.0 \%$ & $5.2 \%$ & $15.6 \%$ & $9.7 \%$ & $4.7 \%$ & $12.5 \%$ & 0.75 & $12.3 \% * * *$ & $0.5 \% * * *$ & $3.1 \% * * *$ \\
\hline Other & $0.0 \%$ & $51.3 \%$ & $0.0 \%$ & $0.0 \%$ & $44.3 \%$ & $0.0 \%$ & Other & . & $7.0 \% * * *$ & . \\
\hline $\mathrm{N}$ & $\begin{array}{l}61430 \\
(0)\end{array}$ & $\begin{array}{c}13,736 \\
(14,462)\end{array}$ & $\begin{array}{c}21222 \\
(0)\end{array}$ & $\begin{array}{c}58651 \\
(0)\end{array}$ & $\begin{array}{c}24,560 \\
(19,519)\end{array}$ & $\begin{array}{c}35313 \\
(0)\end{array}$ & $x^{2}$ & 5461.70 & 2220.61 & 844.74 \\
\hline
\end{tabular}

This table presents the distribution of ending prices for IPOs and non-IPOs and trade types. AT and MM refer to order-book and market maker trades respectively. Quotes are standing orders on the order book. INT is the percentage of integer prices. Other DEC refers to observations that are not in multiples of the minimum tick size. $\mathrm{N}$ refers to the total number of observations. The number of observations not in multiples of the tick size is given in parentheses. 423,307 observations were used. The goodness-of-fit test measures the difference between the IPO and nonIPO price distribution. We hypothesize that the base case for the price distribution is taken from the non-IPO assets and compare the difference between the base case and realized price distribution for IPO assets. *** significant at the $1 \%$ level. 
Table 4: Integer Price Clustering Across Market Segments (\%)

\begin{tabular}{lcccccc}
\hline & & IPO & & & Non-IPO \\
& AT & MM & Quotes & AT & MM & Quotes \\
\hline AIM & $\cdot$ & 51.7 & 89.7 &. & 37.4 & 89.2 \\
AIMI &. & 77.8 & 100,0 &. & 78.4 & 99.6 \\
SEAQ &. & 29.6 & 49.6 &. & 27.0 & 91.8 \\
SEQ1 &. &. &. &. & 80.2 & 100,0 \\
SET1 &. &. &. & 44.2 & 10.5 & 48.1 \\
SET3 & 56.0 & 19.3 & 49.9 &. &. &. \\
SSMM & 64.1 & 35,0 & 53.0 & 63.4 & 44.7 & 44.7 \\
STMM & 72.1 & 42.0 & 65.3 & 59.6 & 37.6 & 52.4 \\
Total & 61.2 & 36.5 & 56.0 & 46.0 & 24.4 & 50.6 \\
\hline
\end{tabular}

This table presents results on integer price clustering for each market segment and new equity issue type (IPOs / non-IPOs). AT and MM refer to order-book and market maker trades respectively. Quotes are standing orders on the order book. AIM and AIMI refer to the domestic and international Alternative Investment Markets respectively (quote-driven). SEAQ is the Stock Exchange Automated Quotation service for non-order book securities (SEQ1, AIM and AIMI). SET1 and SET3 trade on the Stock Exchange Electronic Trading Service (SETS) for liquid securities. SSMM and STMM refer to the hybrid SETSmm service for medium capitalisation and all-but medium capitalisation stocks respectively. 423,307 observations were used. 
Table 5: Intraday Pattern of Clustering (\%)

\begin{tabular}{|c|c|c|c|c|c|c|c|c|c|c|c|c|}
\hline \multirow[b]{3}{*}{ Interval } & \multicolumn{4}{|c|}{ Non-IPO } & \multicolumn{4}{|c|}{ IPO } & \multicolumn{4}{|c|}{ Differences } \\
\hline & \multicolumn{2}{|c|}{$\mathrm{H}(0.5)$} & \multicolumn{2}{|c|}{$\mathrm{Q}(0.25)$} & \multicolumn{2}{|c|}{$\mathrm{H}(0.5)$} & \multicolumn{2}{|c|}{$\mathrm{Q}(0.25)$} & \multicolumn{2}{|c|}{$\mathrm{H}(0.5)$} & \multicolumn{2}{|c|}{$\mathrm{Q}(0.25)$} \\
\hline & AT & MM & AT & $\mathrm{MM}$ & AT & $\mathrm{MM}$ & AT & $\mathrm{MM}$ & AT & $\mathrm{MM}$ & $\mathrm{AT}$ & $\mathrm{MM}$ \\
\hline 08:00 & 55.2 & 30.0 & 42.3 & 28.3 & 93.6 & 76.2 & 72.3 & 42.9 & $-38.4 * * *$ & $-46.2 * * *$ & $-30.0 * * *$ & $-14.6^{* * *}$ \\
\hline 09:00 & 54.1 & 19.5 & 32.4 & 26.0 & 89.4 & 73.1 & 62.0 & 37.0 & $-35.3 * * *$ & $-53.6 * * *$ & $-29.6 * * *$ & $-11.0 * * *$ \\
\hline 09:30 & 54.7 & 19.1 & 33.2 & 23.3 & 86.2 & 71.3 & 56.2 & 33.1 & $-31.5 * * *$ & $-52.2 * * *$ & $-23.0 * * *$ & $-9.8 * * *$ \\
\hline $11: 00$ & 56.9 & 22.8 & 33.5 & 26.8 & 89.7 & 69.6 & 54.4 & 34.8 & $-32.8 * * *$ & $-46.8 * * *$ & $-20.9 * * *$ & $-8.0 * * *$ \\
\hline $11: 30$ & 56.0 & 15.2 & 34.2 & 27.3 & 89.5 & 69.0 & 46.9 & 31.3 & $-33.5 * * *$ & $-53.8 * * *$ & $-12.7 * * *$ & $-4.0 * * *$ \\
\hline $12: 00$ & 53.6 & 22.3 & 41.5 & 16.3 & 75.4 & 69.2 & 53.2 & 34.7 & $-21.8 * * *$ & $-46.9 * * *$ & $-11.7 * * *$ & $-18.4 * * *$ \\
\hline $12: 30$ & 53.8 & 19.9 & 44.2 & 24.7 & 75.6 & 66.2 & 56.4 & 30.8 & $-21.8 * * *$ & $-46.3 * * *$ & $-12.2 * * *$ & $-6.1 * * *$ \\
\hline $13: 00$ & 52.0 & 18.1 & 42.6 & 23.0 & 83.9 & 53.7 & 55.9 & 28.5 & $-31.9 * * *$ & $-35.6^{* * *}$ & $-13.3 * * *$ & $-5.5^{* * * *}$ \\
\hline $15: 00$ & 51.5 & 21.1 & 29.6 & 26.6 & 86.1 & 64.6 & 55.3 & 32.2 & $-34.6 * * *$ & $-43.5 * * *$ & $-25.7 * * *$ & $-5.6^{* * * *}$ \\
\hline $15: 30$ & 49.3 & 21.9 & 33.4 & 26.5 & 83.0 & 59.2 & 58.7 & 34.7 & $-33.7 * * *$ & $-37.3 * * *$ & $-25.3 * * *$ & $-8.2 * * *$ \\
\hline $16: 00$ & 51.9 & 22.0 & 31.6 & 25.7 & 87.2 & 59.5 & 54.2 & 32.8 & $-35.3 * * *$ & $-37.5 * * *$ & $-22.6 * * *$ & $-7.1 * * *$ \\
\hline
\end{tabular}

This table presents the presents the intraday distribution of clustering at integer prices separately for IPOs and non-IPOs controlling for tick size and trade type differences. AT and MM refer to order-book and market maker trades respectively. Price clustering is defined as the percentage of prices in integers. 423,307 observations were used. The goodness-of-fit test measures the difference between the IPO and non-IPO price distribution. We hypothesize that the base case for the price distribution is taken from the non-IPO assets and compare the difference between the base case and the realized price distribution for IPO assets. $* * *$ significant at the $1 \%$ level. 
Table 6: Intraday Aggregated Regression

\begin{tabular}{|c|c|c|c|c|}
\hline \multirow[b]{3}{*}{ Variable } & \multirow[b]{3}{*}{ Expected Sign } & \multicolumn{3}{|c|}{ Coefficient (t value) } \\
\hline & & \multicolumn{2}{|c|}{ Trades } & \multirow{2}{*}{ Quotes } \\
\hline & & AT & MM & \\
\hline \multirow[t]{2}{*}{ Intercept } & & $34.10 * * *$ & $19.18 * * *$ & $43.79 * * *$ \\
\hline & & $(3.11)$ & $(4.14)$ & $(7.69)$ \\
\hline \multirow[t]{2}{*}{ IPO } & + & $23.21 * * *$ & $15.66 * * *$ & $10.24 * * *$ \\
\hline & & $(8.20)$ & $(10.14)$ & $(5.56)$ \\
\hline \multirow[t]{2}{*}{ Under } & + & $0.93 * * *$ & $-0.27 * * *$ & -0.11 \\
\hline & & $(4.12)$ & $(-3.37)$ & $(-1.19)$ \\
\hline \multirow[t]{2}{*}{ Fraction } & - & $10.39^{*}$ & -1.45 & $-5.74 * * *$ \\
\hline & & $(0.08)$ & $(-0.80)$ & $(-2.49)$ \\
\hline \multirow[t]{2}{*}{$\mathrm{TS}$} & + & $9.3 \mathrm{E}-05^{* * *}$ & $-1 \mathrm{E}-05$ & $-6 \mathrm{E}-05^{* * *}$ \\
\hline & & $(2.99)$ & $(-1.47)$ & $(-2.78)$ \\
\hline \multirow[t]{2}{*}{$\mathrm{TF}$} & + & $133.13^{* * *}$ & $-11.53 * * *$ & $24.67 * * *$ \\
\hline & & $(6.31)$ & $(-3.11)$ & $(2.79)$ \\
\hline \multirow[t]{2}{*}{ Segm } & - & -7.73 & $18.14 * * *$ & $34.61 * * *$ \\
\hline & & $(-1.22)$ & $(8.68)$ & $(14.32)$ \\
\hline \multirow[t]{2}{*}{ FS } & - & $-5.43 * * *$ & -0.07 & 0.34 \\
\hline & & $(-3.42)$ & $(-0.12)$ & $(0.48)$ \\
\hline \multirow[t]{2}{*}{$\mathrm{TD}$} & + & 0.04 & $0.10 * * *$ & 0.01 \\
\hline & & $(0.47)$ & $(3.15)$ & $(0.17)$ \\
\hline \multirow[t]{2}{*}{ Vol. } & + & $5.89 * * *$ & $-1.29 * * *$ & -0.66 \\
\hline & & $(5.32)$ & $(-3.57)$ & $(-1.59)$ \\
\hline \multirow[t]{2}{*}{ PL } & + & $0.11 * * *$ & $0.03 * * *$ & $0.01 * * *$ \\
\hline & & $(7.46)$ & $(17.30)$ & $(4.40)$ \\
\hline \multirow[t]{2}{*}{ Tick } & - & $-15.81 * *$ & $-11.76^{* * *}$ & -1.71 \\
\hline & & $(-2.44)$ & $(-3.32)$ & $(-0.53)$ \\
\hline $\mathrm{N}$ & & 405 & 1973 & 987 \\
\hline R-Squared & & 0.47 & 0.22 & 0.39 \\
\hline
\end{tabular}

This table shows the results of the regression analysis. The dependent variable, $C L U S T$ is the percentage of integer numbers for each stock $i$ for each time interval $t$. $I P O$ is an IPO dummy (equals 1 if IPO; 0 otherwise). Under equals negative one times the first-day return. Fraction is a dummy variable that equals 1 if the IPO price is in decimals, zero otherwise. $T S$ is the average trade size per time interval. $T F$ is the inverse square root of the average number of transactions per hour. Segm is a dummy variable that equals 1 if the stock is traded at the main market and 0 otherwise. $F S$ is the natural $\log$ of market capitalization at each day $T$. $T D$ is the percentage of sell orders as a portion of the overall number of trades per interval. VOL is the standard deviation of returns. $P L$ is the average daily closing price for stock i during the study period. Tick equals 1 if $\mathrm{H}$ tick, 0 if Q tick. *,**,*** significant at the $10 \%, 5 \%$ and $1 \%$ levels, respectively. T-statistics are reported. 
Figure 1: Distribution of Decimal Digits (H Tick, Market Maker Trades Only)

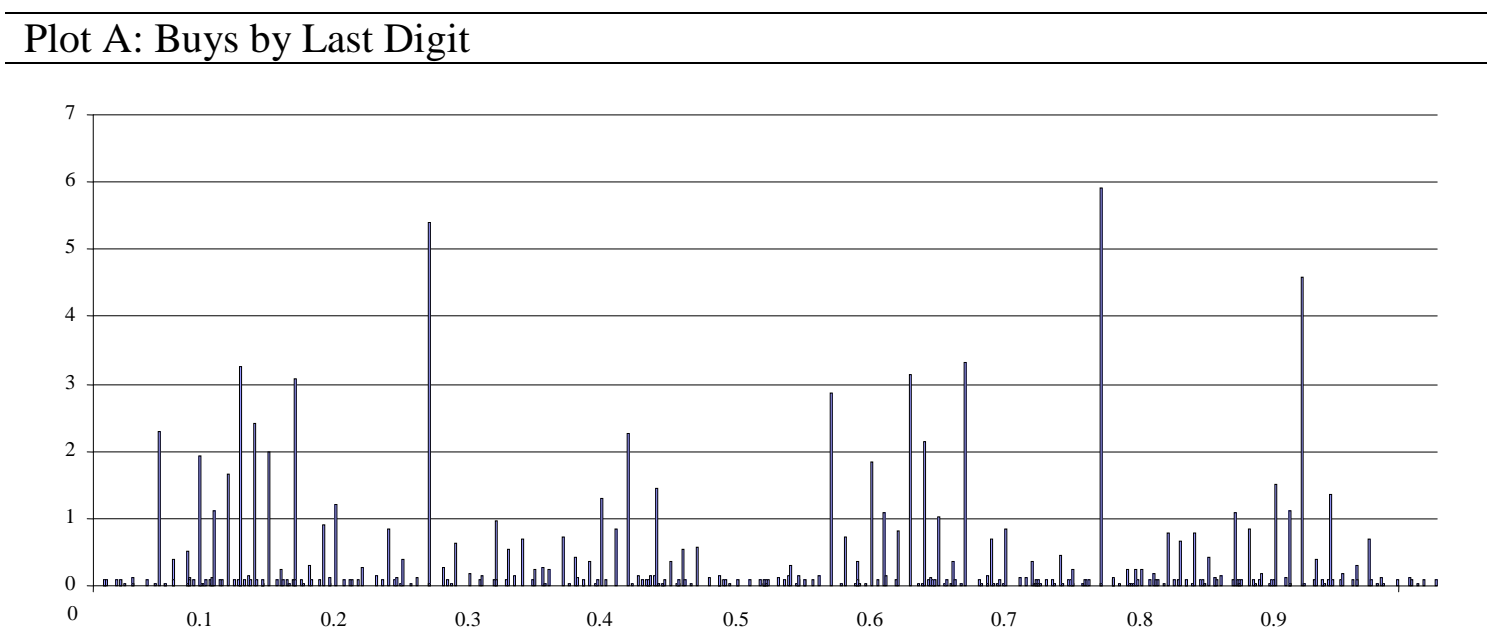

Plot B: Sells by Last Digit

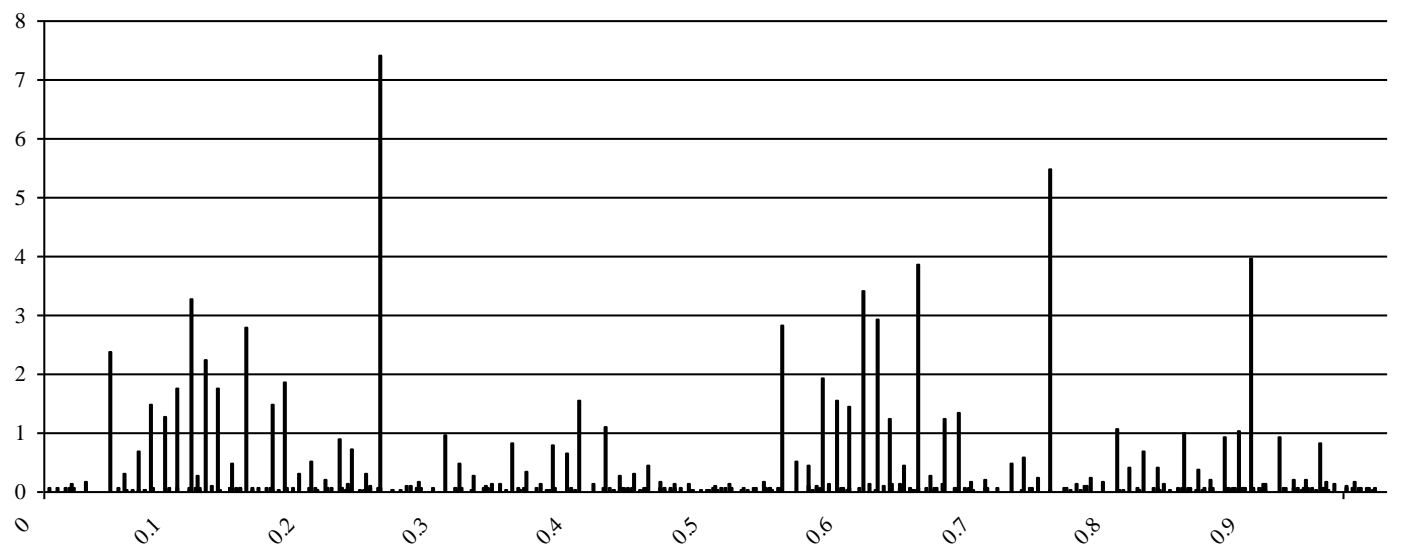

This figure plots the distribution of off-book (MM) trades (excluding the multiples of the minimum price format) for IPOs trading at the H Tick format. 2,571 observations were collected for Graph A and 3,265 for Graph B. Observations that are in multiples of the minimum tick size (0.50) are eliminated in order to enhance the visibility of the graph. 
Figure 2: Distribution of Decimal Digits (Q Tick, Market Maker Trades Only)

Plot A: Buys by Last Digit

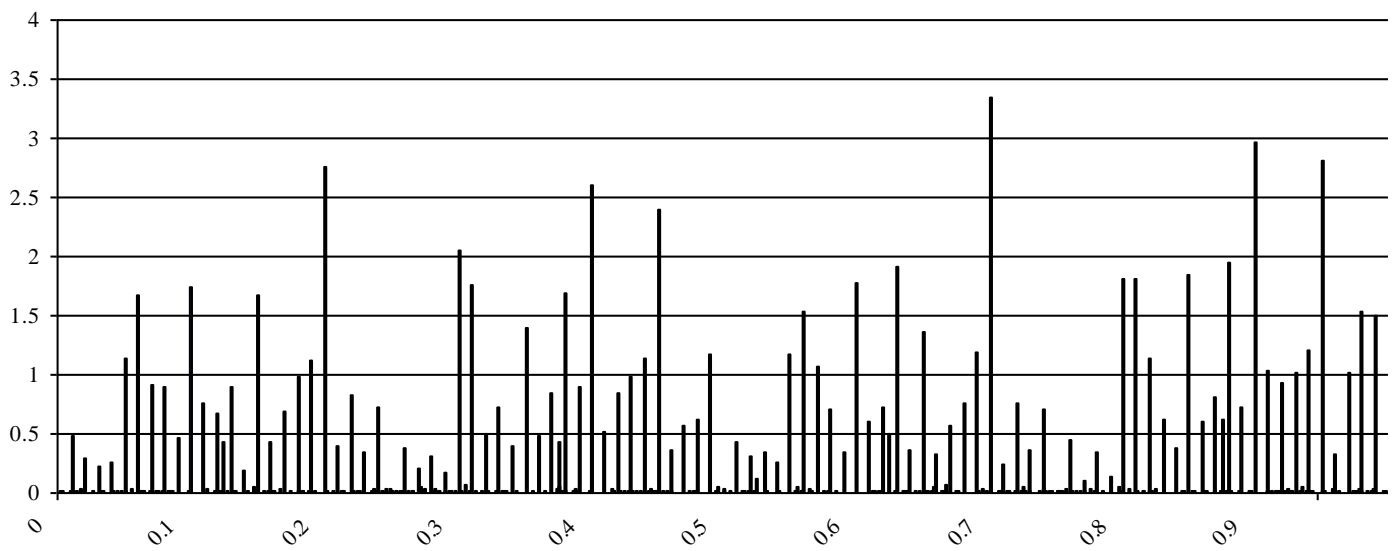

Plot B: Sells by Last Digit

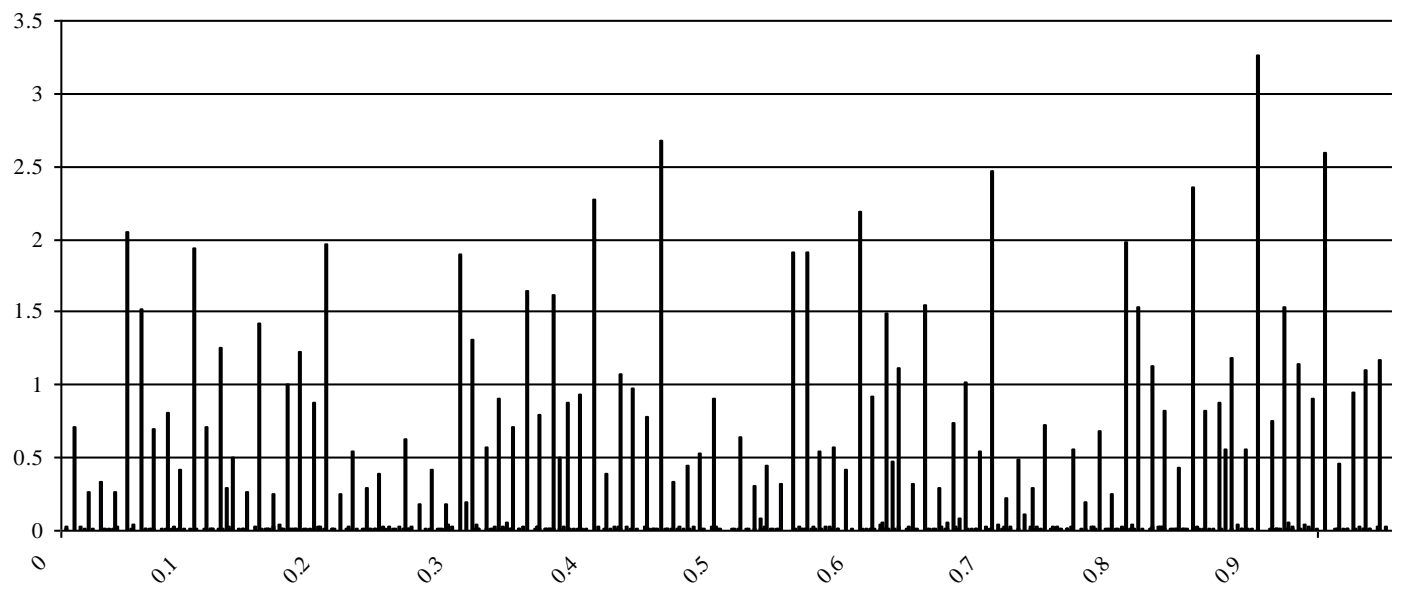

This figure plots the distribution of off-book (MM) trades (excluding the multiples of the minimum price format) for IPOs trading at the Q Tick format. 16,383 observations were collected for Graph A and 18,152 for Graph B. Observations that are in multiples of the minimum tick size $(0.25)$ are eliminated in order to enhance the visibility of the graph. 


\section{References}

Aitken, M., Brown, P., Buckland, C., Izan, H. \& Walter, T., 1996. Price clustering on the Australian stock exchange. Pacific-Basin Finance Journal, 4, 297-314.

Alvarez, S. \& Gonzalez, V. M., 2005. Signalling and the long-run performance of Spanish initial public offerings (IPOs). Journal of Business Finance \& Accounting, 32, 325-350.

Ascioglu, A., Comerton-Forde, C. \& McInish, T. H., 2007. Price clustering on the Tokyo stock exchange. Financial Review, 42, 289-301.

ap Gwilym, O., Clare, A. \& Thomas, S., 1998. Extreme price clustering in the London equity index futures and options markets. Journal of Banking \& Finance, 22, 1193-1206.

ap Gwilym, O., McManus, I. \& Thomas, S., 2005. Fractional versus decimal pricing: evidence from the UK long gilt futures market. Journal of Futures Markets, 25, $419-442$.

Ball, C., Torous, W. \& Tschoegl, A., 1985. The degree of price resolution - the case of the gold market. Journal of Futures Markets, 5, 29-43.

Booth, G. G., \& Yuksel, A., 2006. Price resolution in an emerging market: evidence from the Istanbul stock exchange. European Journal of Finance, 12, 137-152.

Bradley, D. J., Cooney, J. W., Jordan, B. D. \& Ajai, K., 2004. Negotiation and the IPO offer price: a comparison of integer vs. non-integer IPOs. Journal of Financial and Quantitative Analysis, 39, 517-540.

Bristow, D., 1998. IPO price clustering and discreteness. University of California at Los Angeles Working Paper. 
Chen, H.-C., Fauver, L. \& Yang, P.-C., 2009. What do investment banks charge to underwrite American depositary receipts? Journal of Banking \& Finance, 33, 609-618.

Chen, H. C. \& Ritter, J. R., 2000. The seven percent solution. Journal of Finance, 55, $1105-1131$.

Chiao, C. \& Wang, Z.-M., 2009. Price clustering: evidence using comprehensive limit-order data. Financial Review, 44, 1-29.

Christie, W. \& Schultz, P., 1994. Why do NASDAQ market makers avoid odd-eighth quotes? Journal of Finance, 49, 1813-1840.

Chung, K. \& Chiang, S., 2006. Price clustering in e-mini and floor-traded index futures. Journal of Futures Markets, 26, 269-295.

Chung, K., Van Ness, B. \& Van Ness, R., 2004. Trading costs and quote clustering on the NYSE and NASDAQ after decimalization. Journal of Financial Research, 27, 309-328.

Chung, K. H., Kim, K. A. \& Kitsabunnarat, P., 2005. Liquidity and quote clustering in a market with multiple tick sizes. Journal of Financial Research, 28, 177195.

Connolly, D., 2005, The UK trader's bible: the complete guide to trading the UK stock market. Harriman House: Hampshire.

Corwin, S. A., 2003. The determinants of underpricing for seasoned equity offers. Journal of Finance, 58, 2249-2279.

Deloof, M., Maeseneire, W. D. \& Inghelbrecht, K., 2009. How do investment banks value initial public offerings (IPOs)? Journal of Business Finance \& Accounting, 36, 130-160. 
Ellis, K., Michaely, R. \& O'Hara, M., 2000. When the underwriter is the market maker: an examination of trading in the IPO aftermarket. The Journal of Finance, 55, 1039-1074.

Finucane, T. J., 2000. A direct test of methods for inferring trade direction from intraday data. Journal of Financial and Quantitative Analysis, 35, 553-576.

Fishe, R. P. H., 2002. How stock flippers affect IPO pricing and stabilization. Journal of Financial and Quantitative Analysis, 37, 319-340.

Goodhart, C., \& Curcio, R., 1991. The clustering of bid/ask prices and the spread in the foreign exchange market. London School of Economics Working Paper.

Grossman, S., Miller, M., Cone, K., Fischel, D. \& Ross, D., 1997. Clustering and competition in asset markets. Journal of Law \& Economics, 40, 23-60.

Hameed. A. \& Terry, E., 1998. The effect of tick size on price clustering and trading volume. Journal of Business Finance \& Accounting, 25, 849-867.

Hanley, K., 1993. The underwriting of initial public offerings and the partial adjustment phenomenon. Journal of Financial Economics, 34, 231-250.

Harris, L., 1991. Stock price clustering and discreteness. Review of Financial Studies, $4,389-415$.

Harris, L., 2003. Trading and exchanges: market microstructure for practitioners. New York: Oxford University Press.

Huang, R. D., \& Stoll, H., 2001. Tick size, bid-ask spreads, and market structure. Journal of Financial and Quantitative Analysis, 36, 503-522.

Kandel, S., Sarig, O. \& Wohl, A., 2001. Do investors prefer round stock prices? evidence from Israeli IPO auctions. Journal of Banking \& Finance, 25, 15431551 
Mola, S., \& Loughran, T., 2004. Discounting and clustering in seasoned equity offering prices. Journal of Financial and Quantitative Analysis, 39, 1-23.

Moulton, P., 2005. You can't always get what you want: trade size clustering and quantity choice in liquidity. Journal of Financial Economics, 78, 89-119.

Ohta, W., 2006. An analysis of intraday patterns in price clustering on the Tokyo stock exchange. Journal of Banking \& Finance, 30, 1023-1039.

Rocholl, J., 2009. A friend in need is a friend indeed: allocation and demand in IPO bookbuilding. Journal of Financial Intermediation, 18, 284-310.

Torstila, S., 2003. The clustering of IPO gross spreads: international evidence. Journal of Financial and Quantitative Analysis, 38, 673-694.

Wang, Q., 2006. Evolution of integer price clustering of IPOs in the aftermarket University of Minnesota Working Paper. 